\title{
Students' Perception on Blending Instructional 3D Animation in Engineering Courses
}

\author{
Nazirah Mat Sin and Mohammed Awadh M. Al-Asmari
}

\begin{abstract}
Three-dimensional or 3D animation could increase students' learning especially in grasping difficult subject such as engineering subject. Unlike other subjects, implementation of engineering subject is a challenge. One of the problems is the need to provide learners with lab practice and hands-on work. Lab practice and hands-on work are essential in engineering learning as it enables students to look and hold engine parts and to feel its weight and texture and how it's been assembled with smaller parts. It is believed the usage of $3 \mathrm{D}$ animation would be one of a solution to solve the problem. This preliminary study investigates the usefulness of instructional $3 \mathrm{D}$ animation as a learning aid in an electrical engineering course. A cross-sectional survey method has been used as a research design for this pilot study. The study involves 34 students from an engineering course. It has been discovered that majority of the students strongly agree and agree the usage of $3 \mathrm{~d}$ animation should be included as a learning component in engineering subjects.
\end{abstract}

Index Terms-Three-dimensional animation, engineering subject, learning.

\section{INTRODUCTION}

In many countries, integration of animation in learning is an innovative way of teaching to compliment traditional teaching approaches. The urge to integrate three-dimensional animation was to meet the demands of the younger generation learning preference who are already accustomed with technology environment [1]. However, the urge to implement three-dimensional animation in learning was note solely depends on the students' learning need. More importantly, integration of three-dimensional animation was caused by the positive impact that it had on students' learning [2]. Previous studies had showed that computer animations support and help students to understand difficult and complex concept [3]. Enhancement of understanding could be achieved due to three-dimensional animation advantage that provide similar representation of real object in digital form [4]. This enable the students to frequently view the animation until they grasp the content. Consequently, prevented misconceptions among students during learning [5].

Researchers from previous studies had discovered positive outcome when using three-dimensional animation. Firstly, a study about how digital three-dimensional content can enrich and improve science, technology, engineering and

Manuscript received April 24, 2017; revised November 4, 2017.

Nazirah Mat Sin is with Multimedia University, Cyberjaya 63100, Malaysia (e-mail: nazirah.sin@mmu.edu.my).

Mohammed Awadh M. Al-Asmari is with Jeddah International College, Saudi Arabia (e-mail: dhabi_j_s@ @hotmail.com). mathematics learning. Researchers of the study had created a digital 3D model of a human respiratory system, and distributed the model via a web-based platform to three experienced biology lecturers and then conducted in-person interviews with the teachers. The digital 3D model of a human respiratory system offer new possibilities to enhance and enrich science, technology, engineering and mathematics education and improve e-learning, while 2D contents do not always present complete and authentic picture when teaching biology contents [6]. Secondly, a study conducted on learning of peritoneal embryogenesis via three- dimensional imagery have been proven to be significantly more effective as compared to the traditional teaching using static drawings, the superiority of the three-dimensional technique is higher for the dynamic phenomena [7]. The third study on renewable energy system which based on a wind power was introduced within the $3 \mathrm{D}$ virtual environment and taught to students in power systems studies, many more learning activities which were possible in the virtual classroom, comparing to real-world classroom activities, it was obvious that the motivational level of the students in the $3 \mathrm{D}$ virtual environment was higher than in a conventional classroom environment [8].

In general, three-dimensional animation allow learners to observe many phenomena which would be hard or even impossible for them to do so in real world [9]. On top of that, students showed positive learning attitude and experience toward the learning approach [10].

Three-dimensional animation positive impact on students' learning is undeniable. Previous researches that had been reported earlier in this section had discovered and acknowledged three-dimensional influence in enhancing students' understanding in learning and meet the students' learning preference. However, these findings alone are insufficient. Implementation of technical subject especially engineering is a challenge: Implementation of online learning including integration of $3 \mathrm{~d}$ animation had shortened students' time in lab. During lab session, students can feel, hold and manipulate engine parts. On top of that, students could see how these engine parts are assembled during lab session. Thus, integration of 3D animation either to replace or compliment the lab session should be further investigated. This paper aims to report usefulness of instructional 3D animation as a learning aid in an electrical engineering course. Answers gained from this small-scale research would give an indication the relevance of three-dimensional animation in electronical engineering subject.

\section{GOAL OF THE CURRENT STUDY}


Overall this research aims to investigate the significance of using instructional three-dimensional animation as a tool for explaining complicated parts or equipment to student from engineering school.

This study addresses the following research questions:

1) What perceived learning benefits do students of engineering course draw from their utilization of instructional 3D animation?

2) How useful do the students consider instructional $3 \mathrm{D}$ animation as a learning aid in their exploration and study of engineering?

\section{DESIGN OF THE STUDY}

\section{A. Quantitative Research}

Quantitative research had been selected as a research design for this small-scale study. More specifically a cross-sectional survey was selected to gather respondents' opinion on three- dimensional animation as part of learning content. Cross-sectional survey method was utilized in the study in justification that this research study gather data only at one point in time.

\section{B. Participants}

Participants of the study consisted of students from a private higher educational institution students in Cyberjaya, Selangor. Only students from engineering schools involved in the study since the three-dimensional animation related to engineering content. Selection of sample was made using purposive sampling method as the study only involved students with engineering background. On top of that snowball method sampling had been used to seek more participation from engineering students.

The survey reached approximately 200 engineering students through Facebook groups related to the same university, 43 responded the survey, 34 responses out of 43 were valid. The participants were $70 \%$ (24) male and $30 \%$ (10) female. The participant came from different engineering majors from the same faculty, $23.5 \%$ (8) majored in Electrical, 17.6\% (6) majored in Electronics, 29.4\% (10) Electronics Majoring in Telecommunications, 23.5\% (8) Electronics Majoring in Computer, 5.9\% (2) Electronics Majoring in Nanotechnology.

\section{Instrumentation}

A self-administered questionnaire consisted of attitudinal Likert scale questions was designed. The scale indicates the usefulness of three- dimensional animation as a learning aid in engineering courses. The online survey comprises of scale 5 (Strongly Agree), 4 (Agree), 3 (Undecided), 2 (Strongly Disagree) and 1 (Disagree). The participants spent around 5 minutes to complete the survey. Participants of the online survey were given opportunities to rate high or low perception on their view towards questions listed in the questionnaire. The online survey was divided into four sections. The first section contained of questions related to participants' demographic profiles. The second section contained questions related to participants' prior knowledge on utilization of online learning materials. Aside that, participants' acceptance utilization of online learning resources had been asked in this section. Next, in the third section, participants had been given link to watch the threedimensional animation. The last section contained questions related to determined participants' view toward the usefulness of three-dimensional animation in engineering courses.

\section{Procedure}

To seek answer to the research question, an online instrument survey and a link to watch three-dimensional animation from YouTube was used to gather data of the study. The data collection procedure took two weeks to complete. The online survey reached approximately 200 engineering students through Facebook groups from the same university and 43 responded the survey. However, only 34 responses were found valid (see Fig. 1).

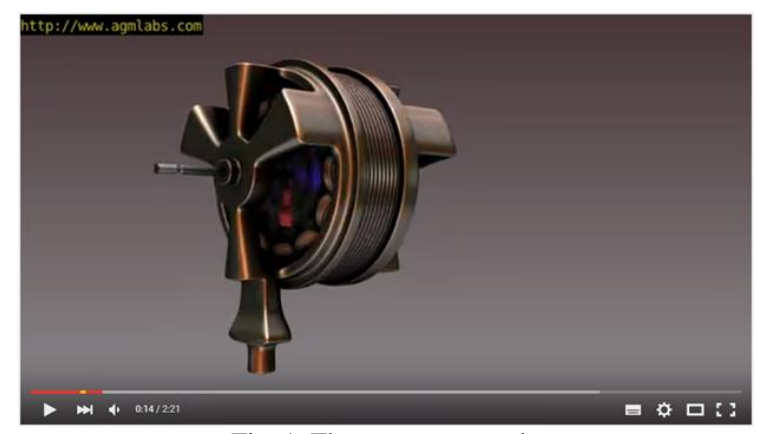

Fig. 1. The survey research.

\section{FINDINGS AND Discussions}

The participants were $70.6 \%$ (24) male and $29.4 \%$ (10) female. $58.8 \%$ (20) of participants were aged from 18 to 24 , where $41.2 \%$ (10) were aged from 25 to 34 . The participant came from different engineering majors from the same faculty, $23.5 \%$ (8) majored in Electrical, $17.6 \%$ (6) majored in Electronics, 29.4\% (10) Electronics Majoring in Telecommunications, $23.5 \%$ (8) Electronics Majoring in Computer, $5.9 \%$ (2) Electronics Majoring in Nanotechnology.

Findings found in this research study is arranged in terms of the research questions presented in this paper:

\section{A. What Perceived Learning Benefits Do Students of Engineering Course Draw from Their Utilization of Instructional 3D Animation?}

The first research question seeks to investigate students' perception on the advantage of three-dimensional animation in engineering subjects.

Participants of the study were requested to rate the learning benefits they gained after using the three- dimensional animation in YouTube. Table I shows how participants answer the seven questions that would determine a conclusion for the research first question. As shown in Table I, students were asked whether the 3D animation content had represented the real object accurately. Majority of the participants had strongly agreed that the $3 \mathrm{~d}$ animation had accurately represent the real object (mean=1.7059) $(\mathrm{Q} 1)$. The participants also strongly agreed $($ mean $=1.2941)$ that three-dimensional animation enabled them to understand the subject (Q2). Next, the participants strongly agreed 
(mean=1.5882) that the concept of the engineering object had been well explained through three-dimensional animation (Q3). In other question (Q6), the participants had strongly agreed (mean=1.5294) that the three-dimensional animation had correctly displayed how a machine worked by displaying its parts moving around as real life machine. Lastly in the seventh question (Q7), participants had strongly agreed (mean=1.7059) that they were able to distinguish the pieces and parts of the motor while they're animating without any difficulties.

TABLE I: PARTICIPANTS OF THE STUDY

\begin{tabular}{|c|c|c|c|c|}
\hline & Minimum & Maximum & Mean & $\begin{array}{l}\text { Std. } \\
\text { Deviation }\end{array}$ \\
\hline $\begin{array}{l}\text { Q1. The 3D } \\
\text { animation } \\
\text { shows the part } \\
\text { as it is in real } \\
\text { life no matter } \\
\text { how small or } \\
\text { how big it is }\end{array}$ & 1.00 & 4.00 & 1.70 & .75996 \\
\hline $\begin{array}{l}\text { Q2. The 3D } \\
\text { animation is } \\
\text { useful to } \\
\text { understanding } \\
\text { the materials }\end{array}$ & 1.00 & 3.00 & 1.29 & .57889 \\
\hline $\begin{array}{l}\text { Q3. The } \\
\text { concepts are } \\
\text { explained } \\
\text { clearly }\end{array}$ & 1.00 & 3.00 & 1.58 & .78306 \\
\hline $\begin{array}{l}\text { Q4. The } \\
\text { instructional } \\
\text { video is } \\
\text { informative }\end{array}$ & 1.00 & 3.00 & 1.76 & .65407 \\
\hline $\begin{array}{l}\text { Q5. The pace in } \\
\text { which I learnt } \\
\text { is appropriate }\end{array}$ & 1.00 & 4.00 & 2.00 & .92113 \\
\hline $\begin{array}{l}\text { Q6. The } \\
\text { animation } \\
\text { enhances the } \\
\text { understanding } \\
\text { of how the } \\
\text { machine works }\end{array}$ & 1.00 & 3.00 & 1.52 & .70648 \\
\hline $\begin{array}{l}\text { Q7. The } \\
\text { animated parts } \\
\text { are clear and } \\
\text { distinct }\end{array}$ & 1.00 & 4.00 & 1.70 & .83591 \\
\hline
\end{tabular}

Based on data presented in Table II, participants of the study had strongly agreed and agreed that three-dimensional animation do bring potential benefits in engineering learning.

TABLE II: The SumMary OF StUdents’ Perceived Potential LEARNING BENEFITS THAT STUDENTS WOULD GAIN IN INSTRUCTIONAL 3D ANIMATION

\footnotetext{
Learning benefits that student's draw from their utilization of instructional 3D animation

- The 3D animation is useful to understanding the materials.

- The animation enhances the understanding of how the machine works.

- The concepts are explained clearly.

- The 3D animation shows the part as it is in real life no matter how small or how big it is.

- The animated parts are clear and distinct.

- The pace in which the students learnt is appropriate.
}

Findings found in the study were similar with previous studies conducted by other researchers. Three-dimensional animation enhanced students' understanding as three-dimensional animation usage gave clear visual demonstration of how a machine works [11]. Additionally, three-dimensional animation in engineering learning had the capability and flexibility of showing parts of machines that consisted of numerous sizes [12]. Participants of the study agreed that the three-dimensional animation help them to distinguish parts of a machine clearly.

\section{B. How Useful Do the Students Consider Instructional 3D Animation As a Learning Aid in Their Exploration and Study of Engineering?}

The second research question seek to investigate students' perception on the usefulness of three-dimensional animation as a learning aid in engineering subjects. Participants of the study were requested to rate the usefulness of the three-dimensional animation in YouTube. A total of five items (Q1, Q2, Q3, Q4, \& Q5) were given to seek answer to the second research question.

As shown in Table III, students were asked on their study preferences between three-dimensional animation over text books: Students agreed that they preferred studying from three-dimensional animation rather studying from text books (mean =1.94). Likewise, in item Q2, participants of the study had strongly agreed that $3 \mathrm{D}$ animation helped the participants to observe on parts and function of engines in more accurate manner $($ mean $=1.70)$. In Q3 item, the participants strongly agreed that utilization of three-dimensional animation in engineering study would increase the possibilities of exploratory study beyond text book (mean $=1.82)$. In Q4 item, the participants strongly agreed the possibility of three-dimensional animation could replace the conventional teaching $($ mean $=1.82)$. Finally, the participants had agreed that they would enroll in online courses which uses instructional 3D animation as a medium of teaching (mean = 1.94). In general, participants of the study showed positive responses toward three-dimensional animation usage in engineering subjects.

TABLE III: PARTICIPANTS PREFERENCES BETWEEN THREE-DIMENSIONAL ANIMATION OVER TEXT BOOKS

\begin{tabular}{|c|c|c|c|c|}
\hline & Minimum & Maximum & Mean & $\begin{array}{c}\text { Std. } \\
\text { Deviation }\end{array}$ \\
\hline $\begin{array}{l}\text { Q1. I would rather } \\
\text { studying from 3D } \\
\text { instructional animation } \\
\text { over text books }\end{array}$ & 1.00 & 4.00 & 1.94 & .95159 \\
\hline $\begin{array}{l}\text { Q2. 3D animation } \\
\text { helps me notice the } \\
\text { parts and its function } \\
\text { accurately }\end{array}$ & 1.00 & 4.00 & 1.70 & .83591 \\
\hline $\begin{array}{l}\text { Q3. The 3D animation } \\
\text { increases the } \\
\text { possibilities for } \\
\text { exploring more aspects } \\
\text { of my study }\end{array}$ & 1.00 & 4.00 & 1.82 & .93649 \\
\hline $\begin{array}{l}\text { Q4. Instructional 3D } \\
\text { animation could replace } \\
\text { traditional teaching due } \\
\text { to its advantages }\end{array}$ & 1.00 & 4.00 & 1.82 & .99911 \\
\hline $\begin{array}{l}\text { Q5. I would enroll in } \\
\text { online courses which } \\
\text { uses instructional 3D } \\
\text { animation as a medium } \\
\text { of teaching }\end{array}$ & 1.00 & 4.00 & 1.94 & .95159 \\
\hline
\end{tabular}


TABLE IV: THE SUMMARY OF STUdEnTs' CONSIDERATION OF InSTRUCTIONAL 3D ANIMATION AS a USEFUl LEARNING AID IN THEIR EXPLORATION AND STUDY OF ENGINEERING (ACCORDING TO HIGHEST TO LOWEST)

Students' consideration of instructional 3D animation as a useful learning aid in their exploration and study of engineering

- 3D animation helps me notice the parts and its function accurately.

- The 3D animation increases the possibilities for exploring more aspects of my study.

- Instructional 3D animation could replace traditional teaching due to its advantages.

- I would rather be studying from 3D instructional animation over text books.

- I would enroll in online courses which uses instructional 3D animation as a medium of teaching.

Multimedia demonstration of a dynamic system with instructional animation provides the students with more accuracy of depiction of the system's behavior comparing to static images [11]. The findings that this study presented similar findings with a previous research study where the results suggested that animation had the potential to improve students' visualization skills when dealing with dynamic objects such as machines and mechanical devises [13]. Thus, engineering students will benefit of using 3D instructional animation as a learning tool in their exploration and study of engineering. Consequently, 3D instructional animation provides easier technique of visualization to learners comparing to traditional teaching.

\section{CONCLUSION}

In summary, the study had found Instructional animation is one of the most superb tools for presenting materials to learner, its significance in helping students to remember and understand information. This study help identifies a conclusion on the impact and benefit that $3 \mathrm{D}$ instructional animation can provide to online programs in term of understanding enhancement in complicated lessons or subjects for the students. The study also found that the 3D instructional animation is valuable and useful to the students in their study for more understanding grasping to the presented information, which will affect back their study validity through online courses. Findings found from this research had strengthened findings reported from previous research studies: Students acceptance of $3 \mathrm{~d}$ animations usage as part of learning tool in their classes. Although the novelty effect is vague, findings found from this research can be used as a foundation for other researchers to further their studies in creating, implementing 3D animation in engineering courses. On top of that, studies should be conducted to relook into the usage, role and effect of textbooks in learning.

\section{REFERENCES}

[1] S. Musa et al., "Introduction to computer animation and its possible educational applications," New Challenges in Education. Retrospection of History of Education to the Future in the Interdisciplinary Dialogue among Didactics of Various School Subjects, pp. 177 -205, 2013.

[2] A. Z. Zare, "High resolution 3D animations as a supplement for the teaching of American sign language," Master's thesis, University of California, Davis, 2011.

[3] J. S. Mtebe and H, M. Twaakyondo, "Are animations effective tools for teaching computer science courses in developing countries?" International Journal of Digital Information and Wireless Communications, vol. 2, no. 2, pp. 202-207, 2012.

[4] D. W. Harris, "An examination of the impact of computer-based animations and visualization sequence on student understanding of hadley cells in atmospheric circulation," Doctoral dissertation, University of Maryland, College Park, MD, 2012.

[5] K. Soika, P. Reiska, and R. Mikser, "The importance of animation as a visual method in learning chemistry," Concept Maps: Making Learning Meaningful, 2010.

[6] L. Siiman et al., "Learning biology with interactive digital 3D content : Teacher attitudes," in Proc. European Conference on e-Learning, pp. 478-485, 2014.

[7] B. Abid et al., "Traditional versus three-dimensional teaching of peritoneal embryogenesis: A comparative prospective study," Surgical and Radiologic Anatomy, vol. 32, no. 7, pp. 1-6, 2010.

[8] H. Aydogan, E. Karakas, F. Aras, and, F. Ozudogru, "3D virtual classroom environment for teaching renewable energy production and substation equipment," International Journal of Electrical Engineering Education, vol. 48, no. 3, pp. 294-306, 2011.

[9] Y. L. Lee, “The development of technological pedagogical content knowledge for science learning with a three-dimensional interactive computer simulation," University of Washington, 2011.

[10] L. Lu, "3D virtual worlds as art media and exhibition arenas Students' responses and challenges in contemporary art education," Studies in Art Education, pp. 232-245, 2013.

[11] E. S. Paik, "Learning with animation and the illusion of understanding," Doctoral dissertation, University of Nevada, Las Vegas, 2010.

[12] C. Rebetez, M. Bétrancourt, M. Sangin, and P. Dillenbourg, "Learning from animation enabled by collaboration," Instructional Science, vol. 38, no. 5, pp. 471-485, 2010.

[13] A. R. Madar, and M. N. Hashim, "Effectiveness of Using graphic animation courseware for students with different cognitive styles and spacial visual abilities," Journal of Technical Education and Training, vol. 3, no. 1, pp. 47-58, 2011.

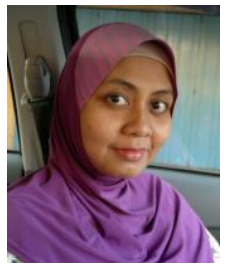

Nazirah Mat Sin obtained her first degree in bachelor of multimedia (honours) (digital media) from Multimedia University, Malaysia in year 2001. She received her master of science (creative multimedia) from the same university in year 2009. In 2010 she obtained her second masters in master of instructional technology from University of Malaya, Malaysia. Her research interests include instructional and educational technology, multimedia, knowledge management. She is currently a lecturer in Faculty of Creative Multimedia, Multimedia University.

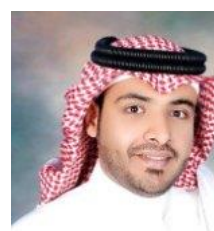

Mohammed Awadh M. Al-Asmari obtained his first degree in bachelor of multimedia (honours) (animation and visual effects) from Multimedia University in 2014. He received his master of multimedia (e-learning technologies) from the same university. His research interests include 3D animation, video production and e-learning. $\mathrm{He}$ is currently a lecturer in Jeddah International College. 